\title{
A computational study of hedgehog signalling involved in basal cell carcinoma reveals the potential and limitation of combination therapy
}

\author{
Antoine Buetti-Dinh ${ }^{1,2,3,4,5^{*}}$ (D), Rebecca Jensen ${ }^{1,2}$ and Ran Friedman ${ }^{1,2}$
}

\begin{abstract}
Background: The smoothened (SMO) receptor is an essential component of the Sonic hedgehog (SHH) signalling, which is associated with the development of skin basal cell carcinoma (BCC). SMO inhibitors are indicated for BCC patients when surgical treatment or radiation therapy are not possible. Unfortunately, SMO inhibitors are not always well tolerated due to severe side effects, and their therapeutical success is limited by resistance mutations.

Methods: We investigated how common are resistance-causing mutations in two genomic databases which are not linked to BCC or other cancers, namely 1000 Genomes and ExAC. To examine the potential for combination therapy or other treatments, we further performed knowledge-based simulations of $\mathrm{SHH}$ signalling, in the presence or absence of SMO and PI3K/Akt inhibitors.

Results: The database analysis revealed that of 18 known mutations associated with Vismodegib-resistance, three were identified in the databases. Treatment of individuals carrying such mutations is thus liable to fail a priori. Analysis of the simulations suggested that a combined inhibition of SMO and the PI3K/Akt signalling pathway may provide an effective reduction in tumour proliferation. However, the inhibition dosage of SMO and PI3K/Akt depended on the activity of phosphodiesterases (PDEs). Under high PDEs activities, SMO became the most important control node of the network. By applying PDEs inhibition, the control potential of SMO decreased and PI3K appeared as a significant factor in controlling tumour proliferation.
\end{abstract}

Conclusions: Our systems biology approach employs knowledge-based computer simulations to help interpret the large amount of data available in public databases, and provides application-oriented solutions for improved cancer resistance treatments.

Keywords: Basal cell carcinoma, Drug resistance, Knowledge-based analysis, Vismodegib, Sonidegib, Erivedge, Odozmo

\footnotetext{
${ }^{*}$ Correspondence: antoine.buetti@Inu.se

'Department of Chemistry and Biomedical Sciences, Linnæus University, Norra vägen 49, SE-391 82 Kalmar, Sweden

2 Linnæus University Centre for Biomaterials Chemistry, Linnæus University,

Norra vägen 49, SE-391 82 Kalmar, Sweden

Full list of author information is available at the end of the article
}

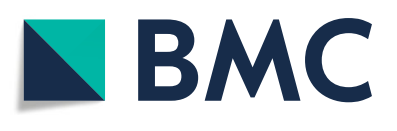

(c) The Author(s). 2018 Open Access This article is distributed under the terms of the Creative Commons Attribution 4.0 International License (http://creativecommons.org/licenses/by/4.0/), which permits unrestricted use, distribution, and reproduction in any medium, provided you give appropriate credit to the original author(s) and the source, provide a link to the Creative Commons license, and indicate if changes were made. The Creative Commons Public Domain Dedication waiver (http://creativecommons.org/publicdomain/zero/1.0/) applies to the data made available in this article, unless otherwise stated. 


\section{Background}

Smoothened (SMO), a 7-pass transmembrane protein, is a component of the Hedgehog $(\mathrm{HH})$ and Patched (PTCH) signalling network responsible for the regulation of cell growth and embryonic development. Mutations that affect the members of this signalling network are associated with the development of skin basal cell carcinomas (BCC) [1] through Gli transcription factors that drive an uncontrolled cell proliferation.

Amino acid mutations in SMO that lead to an unrestrained receptor activity are called activating mutations [2]. Although inhibitors such as vismodegib [3] (Erivedge $^{\circ}$, FDA-approved in 2012) and sonidegib [4] (Odozmo ${ }^{\circ}$, FDA-approved in 2015) that block SMO are available [5], resistance mutations develop after a period of few months thereby limiting the efficacy of those drugs [6]. In addition to amino acid mutations in the receptor, resistance can arise also by a second mechanism that relies on alternative signalling pathways. Biological signalling is typically distributed over multiple components involving converging, diverging and recursive branches of the signalling network. Under selective pressure, tumours can reinforce an alternative signalling route as a response to the blockage of the main signal transduction path. This mechanism of resistance allows cancers to sustain cancerdriving processes such as tumour proliferation despite therapy $[7,8]$.

Resistance mutations provide a selective advantage to the tumour in the face of treatment [9], but may be somewhat deleterious otherwise [10]. To examine whether SMO resistance mutation may pre-exist treatment, or even BCC, the 1000 Genomes [11] and ExAC (Exome Aggregation Consortium) [12] databases were surveyed for such mutations. Owing to the resistance mutations, it is necessary to find therapeutic strategies against $\mathrm{BCC}$ that not only rely on inhibiting SMO, but also focus on other targets in the SMO signalling network. We had previously developed a computational knowledge-based framework to study signalling pathways, especially in the context of cancer [13] and used it to study combination therapies $[14,15]$. Here, we used this approach to predict which signalling pathways need to be targeted by combination therapy, in order to sufficiently impair the development of BCC even if SMO resistance mutations arise.

\section{Results and discussion}

Population occurrence of mutations in the SMO domain make it a difficult target for therapeutic inhibition

40 mutations in 35 amino acid positions were identified in SMO according to the COSMIC database [16] (surveyed in February 2017). Some of these mutations are associated with resistance to SMO inhibitors such as vismodegib
(Table 1). This explains the limited success of these inhibitors.

We further searched for the presence of resistance mutations in two genomic databases that are not linked to BCC or any other cancer, namely 1000 Genomes and ExAC. This analysis (carried out on February 2017), revealed that three resistance mutations were found in the population: W281C (with calculated frequency $p=8.24$. $\left.10^{-6}\right)$, D473N $\left(p=4.13 \cdot 10^{-5}\right)$ and D473H $(p=0.021$, which may be an overestimation since the sample size was only 48). This indicated that normal genetic variation was enough to confer resistance to SMO inhibitors. Of note, in the vast majority of cases, resistance mutations lead to a decrease in the drug's affinity towards its molecular target, which cannot be offset by a higher dose of the drug due to toxicity and intolerance. Combination therapy therefore represents a potential solution to treatment-resistant cancers. Simulation and sensitivity analysis of the SMO signalling network were used to identify optimal signalling targets for a combination therapy against drug-resistant BCC.

\section{Signalling pathway analysis identified PI3K/Akt and PDEs as potential targets for treatment of BCC}

The SMO signalling network was simulated in order to identify potential molecular targets for therapy (Fig. 1). In the simulations of the signal transduction network, the

Table 1 Known resistance mutations in the SMO domain. Source: COSMIC http://cancer.sanger.ac.uk/cosmic [16]

\begin{tabular}{lll}
\hline Mutation & Number & Associated with \\
& of samples & BCC initiation \\
\hline H231R & 2 & Yes \\
T241M & 1 & No \\
W281C & 2 & Yes \\
W281L & 1 & No \\
V321A & 1 & Yes \\
V321M & 3 & Yes \\
A459V & 3 & Yes \\
F460L & 1 & Yes \\
C469Y & 1 & No \\
D473G & 7 & Yes \\
D473H & 2 & Yes \\
D473N & 1 & Yes \\
D473Y & 1 & No \\
Q477E & 1 & Yes \\
G497W & 3 & Yes \\
S533N & 1 & Yes \\
W535L & 10 & Yes \\
W535R & 1 & Yes \\
\hline
\end{tabular}




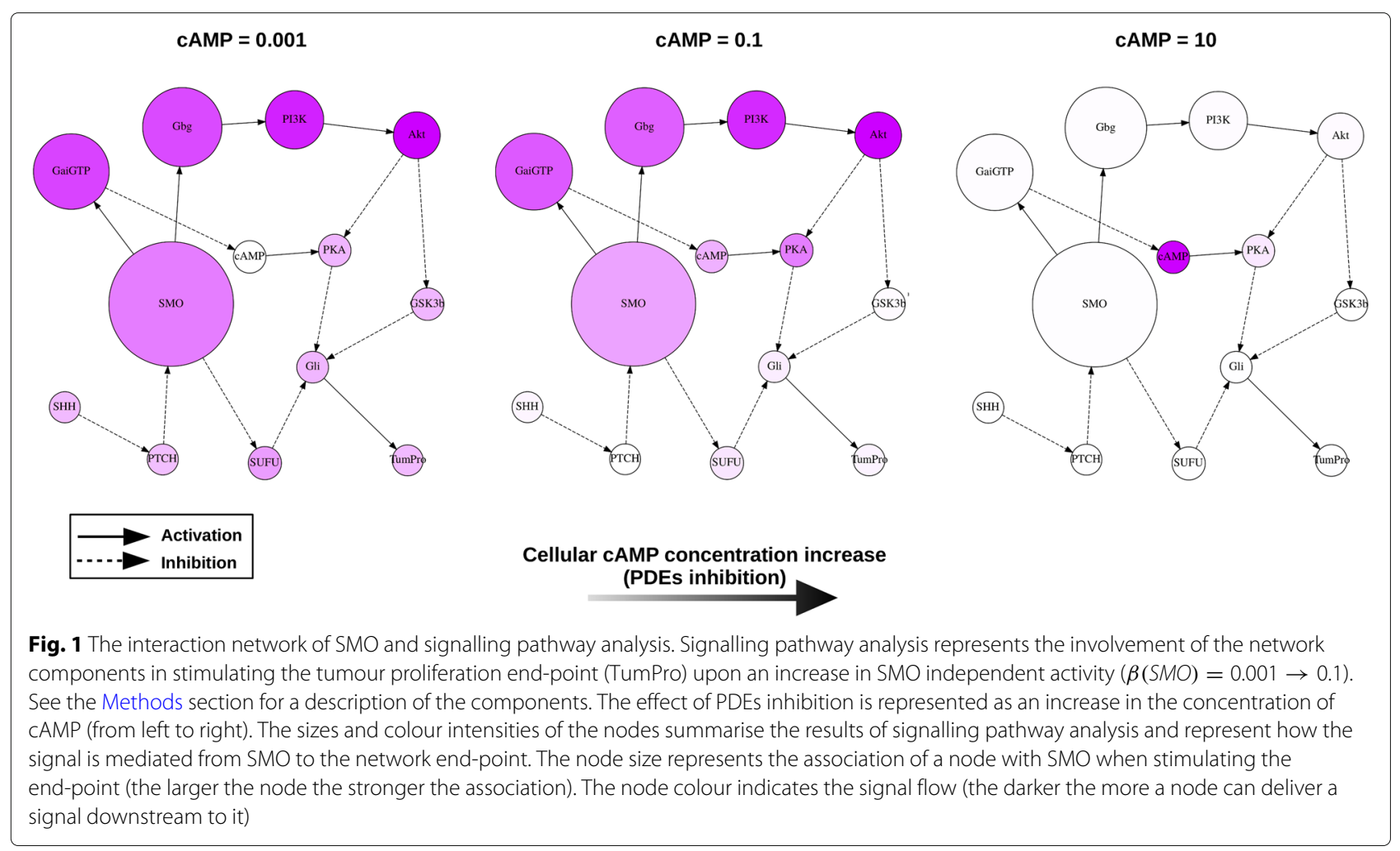

signals are transmitted between the different components of the network through activation or inhibition, which culminate in the cancer-promoting end-point "tumour proliferation" (TumPro). The simulations were performed by applying a coarse-grained approach [15] whereby exhaustive simulations of the network states were carried out in which each node assumed one of two possible states: "low activity" or "high activity" (see Methods section). This enabled us to identify the network states that were most significant for the development of high tumour proliferation, and consequently, the signalling pathways relevant for therapeutic intervention.

\section{Knowledge-based simulations highlight the important role of PI3K/Akt signalling}

Analysis of the simulations suggested that upon an independent activity increase of SMO (for example due to an activating mutation), signalling to the tumour proliferation end-point is mediated principally by the pathway involving the PI3K and Akt kinases (left panel in Fig. 1). The degree of association between each node and SMO's activity is indicated by its size in the figure. In addition, each node's signal flow intensity was represented proportionally to the node's colour intensity, i.e., the darker the node the more active it was when the control node (SMO) was highly active. Both measures indicated the PI3K/Akt pathway as the main signalling route to stimulate tumour proliferation. Thus, analysis of the simulations revealed that a combined inhibition of SMO and of the PI3K/Akt pathway branch would be an effective therapeutic strategy against BCC, in agreement with other studies $[5,17]$. Unfortunately, inhibition of the PI3K/Akt pathway is difficult to achieve $[18,19]$. Interestingly, the simulations also indicated Cyclic adenosine monophosphate (cAMP) as a potential network control point for reducing tumour proliferation. Cyclic nucleotide phosphodiesterases (PDEs) are enzymes that catalyse the degradation of a phosphodiesther bond in CAMP or cGMP, and are thus potential molecular targets for intervention (inhibition of PDEs leads to an increase of the concentration of free cAMP).

\section{Inhibition of PDEs may reduce tumour proliferation}

Several, selective and non-selective PDEs inhibitors are currently available and have the effect to increase intracellular cAMP [20, 21]. PDEs inhibitors have been employed to treat several diseases [22] including different types of cancers such as oral squamous carcinoma [23], colon $[24,25]$ and breast cancer [26]. Roflumilast (Daliresp ${ }^{\circ}$, FDA-approved in 2011 to treat chronic obstructive pulmonary diseases) is a PDE4 inhibitor also used to treat B-cell malignancies [27].

By simulating an increase in cAMP $(\beta(c A M P)$ from 0.001 to 0.1 ), the SMO network became less branched: the nodes GSK3b and SUFU became less involved in conveying signalling from SMO to the tumour proliferation end-point (TumPro). In addition, the steady-state 
activity of the tumour proliferation end-point was reduced (compare the left with the central panel in Fig. 1). Ultimately, simulations of very strong PDEs inhibition, where the resulting cAMP concentration compares to a 100-fold higher activity with respect to the high nodes' activity level $(\beta=0.1)$ assumed in the network simulation, revealed a bottleneck where the only relevant control node for the signal flow in this extreme situation is cAMP (see right panel in Fig. 1).

\section{Network control analysis reveals changes in the significance of SMO and PI3K as a function of circulating cAMP}

Sensitivity analysis of the SMO network was carried out by simulating small variations in the activity of the SMO and PI3K. By following earlier studies $[13,14]$, this enabled us to identify activity ranges where control of tumour proliferation is possible through inhibition of SMO and PI3K, in combination with different levels of cAMP (corresponding to different PDEs inhibition strengths, see Fig. 2).

At low cAMP (no PDEs inhibition), tumour proliferation had a high steady-state activity (not shown), and was rather insensitive to variation in PI3K and SMO (see lower heatmaps in Fig. 2). Increasing cAMP (i.e., applying PDE inhibition), improved the controllability of the system by both SMO and PI3K: a region of high sensitivity formed between low and high SMO and PI3K activities (see left and right panels of Fig. 2, respectively). This corresponds to a transition zone between low and high steady-state activity of tumour proliferation, and indicates the presence of controllable regions (with respect to variations in SMO or PI3K). Combined inhibition that targets SMO and $\mathrm{PI} 3 \mathrm{~K}$ in correspondence to these regions (with respect to a maximal level of SMO and PI3K activities) is thus suggested to be effective in reducing tumour proliferation.

Network control analysis suggested that the effect of dual inhibition of SMO and PI3K differed depending on the PDEs activity (see peak (maximal) sensitivity values in Table 2 corresponding to the different conditions of Fig. 2). At low and intermediate $\operatorname{cAMP}(\beta(c A M P)=0.001$ and $\beta(c A M P)=0.1$, respectively), the system's highest sensitivity values were obtained by variations in SMO activity, i.e., the network end-point's controllability primarily depended on variations in SMO activity $(0.00024$ and 0.00619 , respectively); and secondarily on PI3K activity variations (0.00019 and 0.00521, respectively). In contrast, when the cAMP level was high (corresponding to a very strong PDEs inhibition), the end-point's controllability showed a stronger dependence on PI3K than on SMO activity variations (0.02538 versus 0.01380$)$. Therefore, under no and moderate PDEs inhibition $(\beta(c A M P) \leq$ 0.1 ), SMO was $\sim 20$ more influential than PI3K for controlling tumour proliferation, while at high PDEs inhibition $(\beta(c A M P)=10)$ PI3K was $\sim 20 \%$ more determinant than SMO for the end-point control.

\section{Combined inhibition of network control points revealed by principal component analysis}

Principal component analysis (PCA) was used to detect co-activity and co-regulatory patterns (when it was applied to steady-state and sensitivity values, respectively) between the signalling components at the different cAMP levels applied in the network control analysis dataset presented in section "Signalling pathway analysis identified PI3K/Akt and PDEs as potential targets for treatment of BCC". Sensitivity PCA showed that by increasing cAMP from a low level, a cluster formed that included cAMP and

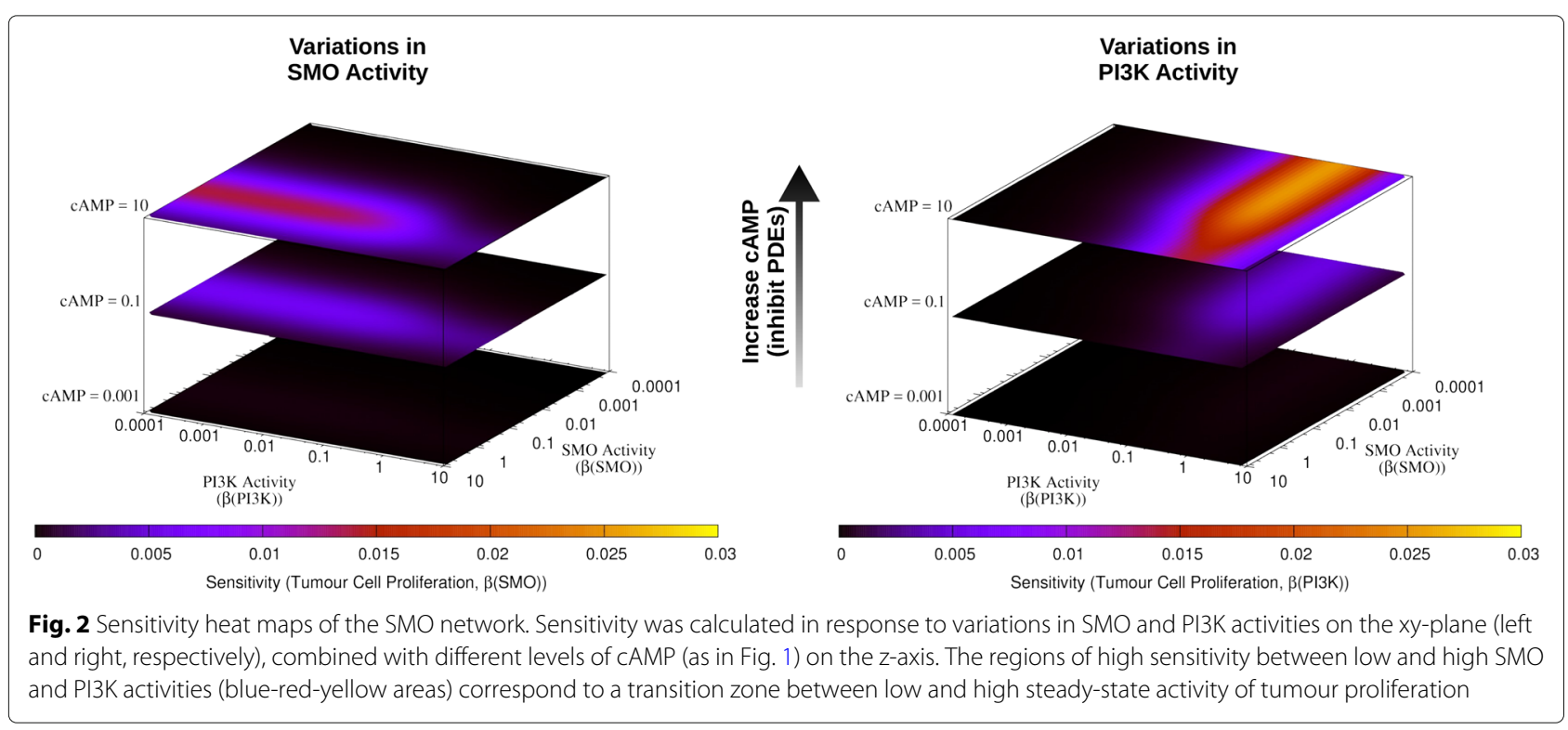


Table 2 Peak sensitivity values for the conditions represented in Fig. 2

\begin{tabular}{llll}
\hline & $\beta($ CAMP $)=0.001$ & $\beta($ CAMP $)=0.1$ & $\beta($ CAMP $)=10$ \\
\hline $\begin{array}{l}\text { Variations in } \\
\text { SMO Activity }\end{array}$ & 0.00024 & 0.00619 & 0.01380 \\
$\begin{array}{l}\text { Variations in } \\
\text { Pl3K Activity }\end{array}$ & 0.00019 & 0.00521 & 0.02538 \\
\hline
\end{tabular}

PKA (see Additional file 1: Figures S1-S3). This analysis thus supports the earlier conclusion that cAMP influences the signal transduction through PKA and that it can act as a regulator in addition to the PI3K/Akt pathway, as suggested before by signalling pathway analysis in section "Inhibition of PDEs may reduce tumour proliferation". Furthermore, SMO clustered with nodes directly downstream of it (Gbg and GaiGTP) at low and intermediate cAMP (see Additional file 1: Figures S1 and S2). When cAMP was high, this cluster merged with PI3K and Akt, suggesting that strong PDEs inhibition and consequent increase of cAMP causes the network components PI3K, Akt and SMO and their downstream partners (Gbg and GaiGTP) to become co-regulated (see Additional file 1: Figure S3). A combination of PDEs inhibition that causes an increase in cAMP, together with inhibition of the SMO and the PI3K/Akt pathway is therefore predicted to counter tumour proliferation.

\section{Conclusions}

SMO is subject to various amino acid mutations or variations which apparently do not hamper its activity. Some of these mutations provide a basis for developing resistance mutations against therapeutic inhibitors, which is one reason that makes SMO a challenging target for $\mathrm{BCC}$ therapies. We performed simulations of the $\mathrm{SHH} / \mathrm{SMO}$ interaction network in BCC in order to identify signalling pathways that could confer resistance to treatments. Our approach enabled the identification of potential treatment combinations effective against forms of BCC harbouring resistance mutations in SMO.

The simulations suggested that upon an increase in SMO activity, the PI3K/Akt signalling plays a crucial role in promoting tumour proliferation. Combined inhibition of SMO and PI3K was studied in detail together with the effect of different levels of cAMP (PDE inhibition). Our results indicate a complex regulation of SMO and PI3K as a function of PDEs activity. SMO was the most important control node of the network at no and moderate inhibition of PDEs. However, under strong PDEs inhibition, the systems became more sensitive to both SMO and PI3K, but PI3K became more relevant than SMO for controlling tumour proliferation. PI3K was previously suggested to be involved in acquired resistance to treatments against refractory tumours $[5,17]$. Our simulations propose a mechanism based on activation/inhibition of signalling components in the SMO network, where PDEs determine the outcome of therapies that target the PI3K signalling. These results provide quantitative insights into the signalling network of $\mathrm{SHH} / \mathrm{SMO}$ involved in $\mathrm{BCC}$, and suggest that a combined inhibition with different dosages of SMO, PDE and PI3K/Akt inhibitors may be required to tackle drug-resistant BCC.

\section{Methods}

Simulations of the SMO signalling network

A signalling network model of SMO and its principal interaction partners described in the literature was constructed based on the current state of knowledge [5, 28-36] (see Fig. 1). SMO is negatively regulated by the transmembrane receptor $\mathrm{PTCH}$. SHH derepresses the PTCH-mediated effect on SMO. Through different intermediates, this leads to the activation of the Gli family of transcription factors, which in turn activate genes involved in tumour proliferation [30, 31]. Downstream of $\mathrm{SMO}, \mathrm{G} \alpha_{i}$ proteins decrease the level of cAMP upon Guanosine-5'-triphosphate (GTP) hydrolysis (indicated as GaiGTP); and consequently prevent the inhibitory phosphorylation of Gli by protein kinase A (PKA). In parallel, $\mathrm{G} \beta \gamma$ (Gbg) subunits inhibit PKA through the PI3K/Akt (phosphoinositide 3 kinase / protein kinase B) pathway $[32,33]$. This relieves the glycogen synthetase kinase $3 \beta$ (GSK3b)-mediated inhibition of Gli proteins [34, 35]. Furthermore, SMO also relieves the inhibition of the suppressor of fused (SUFU) onto Gli proteins further enhancing the tumour proliferation effect $[30,36]$.

The interaction network model of SMO signalling was simulated with the computational method developed by us previously $[13,14]$. The network's nodes represented signalling components as a set of ordinary differential equations (ODEs). Edges represented the interaction links between the components (modelled as empirical Hilltype transfer functions). This enabled the integration of experimental information in the modelling framework in a straightforward way using a well-established formalism derived from classical enzyme kinetics. This approach requires only the knowledge necessary to set up Boolean models (where interaction is assumed to be binary, i.e., activation or inhibition). Despite its simplicity, the analysis of such simulations provides quantitative insights on studied signalling networks, taking into account nonlinear signalling effects such as feedbacks, pleiotropy and redundancy. This way, our method allows to analyse computationally disease networks for which detailed experimental information is not available.

The simulation procedure yielded steady-state activity levels of the different network components according to a given set of parameters. The range of independent activities of the different network components $(\beta)$ 
is summarised in Additional file 1: Table S1 (see reference [13] for a complete list of parameters available in our code). Sensitivity analysis was applied to the resulting steady-state activities by calculating the sensitivity corresponding to each parameter change. Steady-state simulations and sensitivity analysis were carried out using parallel computational architectures in order to screen a large number of conditions and identify key control points of the network. This enabled us to methodically characterise the effect of inhibition of SMO and PI3K under the different levels of PDEs activity.

\section{Simulation and sensitivity in signalling pathway analysis}

The analysis of signalling pathways involved in tumour proliferation consisted of enumerating all combinations of network states with high $(\beta=0.1)$ or low $(\beta=0.001)$ initial activity state (see Additional file 1: Table S1). For each pairwise combination of parameters (where the network state differs by the activity of a single node), sensitivity was calculated according to the method used in reference [15], i.e.,

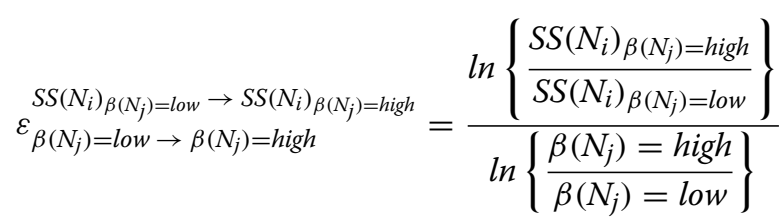

where $S S(N)$ denotes the steady-state activity of a node $N$ and $\beta(N)$ its independent activity state. The arrow $(\rightarrow)$ indicates a change in condition.

Without considering the combined activity change of multiple control nodes simultaneously, but only the changes occurring subsequently one after another (as it would be expected by point mutations affecting the activity of a protein), Eq. 1 allows to calculate the $s^{n}$ conditions that represent all possible states of the network $(s$ is the number of states a node can assume, $n$ is the number of nodes in the network).

Sensitivity is subsequently computed for each pair of simulated conditions that differ by a single parameter (i.e., pair of simulations where the network states are identical except for a single node that is low in the first simulation and high in the second, or vice versa). This resulted in a set of calculated sensitivities derived from the coarse-grained simulations that comprises $s^{n} \cdot \frac{n}{s} \cdot(s-1)$ sensitivity values from which signal flow graphs are computed (see Fig. 1).

The obtained sensitivity values represent the strength of the influence exerted by a node, connected directly or through intermediates, onto another component of the network. A positive value for the sensitivity between two nodes $(\mathrm{A} \rightarrow \mathrm{B})$ indicates that upon the increase of the activity of A, B's activity will also increase. Similarly, a negative sensitivity indicates that upon an increase of A's activity, B's activity will decrease. Sensitivity values close to 0 indicated independence between nodes. Signal flow graphs (see Fig. 1) were built based on the node's activity and on the calculated sensitivity values. They represent how the signal travels from the control node (node subject to an increase in independent activity) to the network end-points. Upon activation of the control node, the statistical association of other nodes that are influenced is represented by the graph's node area (the larger the stronger the association). The colour of the nodes indicates their activity contribution (the darker is a node, the stronger is the signal it can deliver downstream to it).

\section{Simulation and sensitivity in network control analysis}

Based on the same mathematical principles as for in the signalling pathway analysis, in network control analysis the majority of the network components were assumed to have a low (resting) activity, while few nodes, identified by signalling pathway analysis as relevant for controlling the network behaviour, were varied over a range of activities $(\beta)$ in small steps (as explained in reference [15] and expanded in Additional file 1: Table S1). This yielded a more detailed characterisation of those nodes that were critical for controlling the network end-points and consequently relevant for cancer development.

\section{Principal component analysis and hierarchical clustering}

PCA was used as a multivariate analysis to reduce dimensionality of the simulation dataset of the network control analysis (the prcomp function of $\mathrm{R}$ was used as a part of the computational method developed by us previously $[13,14])$. It was applied to visualise PCA loadings (corresponding to the network components) of steady-state and sensitivity data on a two-component space (as presented in the top panels in Additional file 1: Figures S1-S3). PCA loadings were further classified using hierarchical clustering (the hclust function of $\mathrm{R}$ was used) and represented in a tree-like structure (dendrogram) whose branches grouped network components according to their similarity over the different simulations (displayed in the bottom dendrograms of Additional file 1: Figures S1-S3).

\section{Additional file}

Additional file 1: Supplementary Material. PCA at different levels of CAMP and model parameters. (PDF $1380 \mathrm{~kb}$ )

\section{Abbreviations}

BCC: Basal cell carcinoma; CAMP: Cyclic adenosine monophosphate; ExAC: Exome Aggregation Consortium; GTP: Guanosine-5'-triphosphate; HH: Hedgehog; ODEs: Ordinary differential equations PTCH: Patched; PDEs: Cyclic nucleotide phosphodiesterases; PCA: Principal component analysis; PKA:

Protein kinase A; SMO: Smoothened; SUFU: Suppressor of fused 


\section{Funding}

This work was supported by The Swedish Cancer Society (Cancerfonden), project number CAN 2015/387 to RF. The funders of this project had no role in the design of the study and collection, analysis, and interpretation of data and in writing the manuscript.

\section{Availability of data and materials}

The datasets generated and/or analysed during the current study are available in the Figshare repository (DOI: 10.6084/m9.figshare.5472490).

\section{Authors' contributions}

$A B D$ carried out the simulations, performed the analysis of the data and drafted the initial manuscript. RJ searched the databases and performed the analysis of the public data. RF initiated, supervised the project and participated in the data analysis. ABD and RF wrote the manuscript.

\section{Ethics approval and consent to participate}

Not applicable

\section{Competing interests}

The authors declare that they have no competing interests.

\section{Publisher's Note}

Springer Nature remains neutral with regard to jurisdictional claims in published maps and institutional affiliations.

\section{Author details}

1Department of Chemistry and Biomedical Sciences, Linnæus University, Norra vägen 49, SE-391 82 Kalmar, Sweden. . ${ }^{2}$ Linnæus University Centre for Biomaterials Chemistry, Linnæus University, Norra vägen 49, SE-391 82 Kalmar, Sweden. ${ }^{3}$ Centre for Ecology and Evolution in Microbial Model Systems, Linnæus University, Landgången 3, SE-391 82 Kalmar, Sweden . ${ }^{4}$ Institute of Computational Science, Faculty of Informatics, Università della Svizzera Italiana, Via Giuseppe Buffi 13, CH-6900 Lugano, Switzerland. ${ }^{5}$ Swiss Institute of Bioinformatics, Quartier Sorge - Batiment Genopode, CH-1015 Lausanne, Switzerland

\section{Received: 5 February 2018 Accepted: 30 April 2018}

Published online: 18 May 2018

\section{References}

1. Epstein EH. Basal cell carcinomas: attack of the hedgehog. Nat Rev Cancer. 2008;8(10):743-54. https://doi.org/10.1038/nrc2503. PubMed Central: PMC4457317. [PubMed: 18813320].

2. Xie J, Murone M, Luoh SM, Ryan A, Gu Q, Zhang C, Bonifas JM, Lam CW Hynes M, Goddard A, Rosenthal A, Epstein EH, de Sauvage FJ. Activating Smoothened mutations in sporadic basal-cell carcinoma. Nature. 1998:391(6662):90-2. https://doi.org/10.1038/34201. PubMed: 9422511.

3. Cirrone F, Harris CS. Vismodegib and the hedgehog pathway: a new treatment for basal cell carcinoma. Clin Ther. 2012:34(10):2039-50. https://doi.org/10.1016/j.clinthera.2012.08.011. PubMed: 23036338.

4. Pan S, Wu X, Jiang J, Gao W, Wan Y, Cheng D, Han D, Liu J, Englund NP, Wang Y, Peukert S, Miller-Moslin K, Yuan J, Guo R, Matsumoto M, Vattay A, Jiang Y, Tsao J, Sun F, Pferdekamper AC, Dodd S, Tuntland T, Maniara W, Kelleher JF, Yao YM, Warmuth M, Williams J, Dorsch M. Discovery of NVP-LDE225, a Potent and Selective Smoothened Antagonist. ACS Med Chem Lett. 2010;1(3):130-4. https://doi.org/10. 1021/ml1000307. PubMed Central: PMC4007689. PubMed: https://www. ncbi.nlm.nih.gov/pubmed/24900187.

5. Athar M, Li C, Kim AL, Spiegelman VS, Bickers DR. Sonic hedgehog signaling in Basal cell nevus syndrome. Cancer Res. 2014;74(18):4967-75. https://doi.org/10.1158/0008-5472.CAN-14-1666. PubMed Central: PMC4167483. PubMed: 25172843.

6. Pricl S, Cortelazzi B, Dal Col V, Marson D, Laurini E, Fermeglia M, Licitra L, Pilotti S, Bossi P, Perrone F. Smoothened (SMO) receptor mutations dictate resistance to vismodegib in basal cell carcinoma. Mol Oncol. 2015;9(2):389-97. https://doi.org/10.1016/j.molonc.2014.09.003. PubMed: 25306392.

7. Rathert $P$, Roth $M$, Neumann T, Muerdter F, Roe JS, Muhar M, Deswal S, Cerny-Reiterer S, Peter B, Jude J, Hoffmann T, Boryń LM, Axelsson E, Schweifer N, Tontsch-Grunt U, Dow LE, Gianni D, Pearson M, Valent P,
Stark A, Kraut N, Vakoc CR, Zuber J. Transcriptional plasticity promotes primary and acquired resistance to BET inhibition. Nature. 2015;525(7570) 543-7. https://doi.org/10.1038/nature14898. PubMed Central: PMC4921058. PubMed: 26367798.

8. Fong CY, Gilan O, Lam EY, Rubin AF, Ftouni S, Tyler D, Stanley K, Sinha D, Yeh P, Morison J, Giotopoulos G, Lugo D, Jeffrey P, Lee SC, Carpenter C, Gregory R, Ramsay RG, Lane SW, Abdel-Wahab O, Kouzarides T, Johnstone RW, Dawson SJ, Huntly BJ, Prinjha RK, Papenfuss AT, Dawson MA. BET inhibitor resistance emerges from leukaemia stem cells. Nature. 2015;525(7570):538-42. https://doi.org/10. 1038/nature14888. PubMed: 26367796.

9. Friedman R. Drug resistance in cancer: molecular evolution and compensatory proliferation. Oncotarget. 2016;7(11):11746-55. https:// doi.org/10.18632/oncotarget.7459. PubMed Central: PMC4914245. PubMed: 26909596

10. Friedman R. Drug resistance missense mutations in cancer are subject to evolutionary constraints. PLOS ONE. 2013;8(12):82059. https://doi.org/10. 1371/journal.pone.0082059. PubMed Central: PMC3869674. PubMed: 24376513.

11. Auton A, Brooks LD, Durbin RM, Garrison EP, Kang HM, et al. A global reference for human genetic variation. Nature. 2015;526(7571):68-74. https://doi.org/10.1038/nature15393. PubMed: 26432245. PubMed Central: PMC4750478.

12. Lek M, Karczewski KJ, Minikel EV, Samocha KE, Banks E, et al. Analysis of protein-coding genetic variation in 60,706 humans. Nature. 2016;536(7616):285-91. https://doi.org/10.1038/ nature1905710.1038/nature19057. PubMed Central: PMC5018207. PubMed: 27535533

13. Buetti-Dinh A, Pivkin IV, Friedman R. S100A4 and its role in metastasis computational integration of data on biological networks. Mol Biosyst. 2015;11(8):2238-46. https://doi.org/10.1039/c5mb00110b. PubMed: 26118552.

14. Buetti-Dinh A, Pivkin IV, Friedman R. S100A4 and its role in metastasis simulations of knockout and amplification of epithelial growth factor receptor and matrix metalloproteinases. Mol Biosyst. 2015;11 (8):2247-54. https://doi.org/10.1039/c5mb00302d. PubMed: 26057862.

15. Buetti-Dinh A, O'Hare T, Friedman R. Sensitivity Analysis of the NPM-ALK Signalling Network Reveals Important Pathways for Anaplastic Large Cell Lymphoma Combination Therapy. PLoS ONE. 2016;11(9):0163011. https://doi.org/10.1371/journal.pone.0163011. PubMed Central: PMC5036789. PubMed:27669408.

16. Forbes SA, Beare D, Bindal N, Bamford S, Ward S, Cole CG, Jia M, Kok C, Boutselakis H, De T, Sondka Z, Ponting L, Stefancsik R, Harsha B, Tate J, Dawson E, Thompson S, Jubb H, Campbell PJ. COSMIC: High-Resolution Cancer Genetics Using the Catalogue of Somatic Mutations in Cancer. Curr Protoc Hum Genet. 2016;91:1-10. https://doi.org/10.1002/cphg.21. PubMed: 27727438

17. Engelman JA, Settleman J. Acquired resistance to tyrosine kinase inhibitors during cancer therapy. Curr Opin Genet Dev. 2008;18(1):73-9. https://doi.org/10.1016/j.gde.2008.01.00410.1016/j.gde.2008.01.004. PubMed: 18325754

18. Massacesi $C$, Di Tomaso E, Urban $P$, Germa C, Quadt C, Trandafir L, Aimone P, Fretault N, Dharan B, Tavorath R, Hirawat S. PI3K inhibitors as new cancer therapeutics: implications for clinical trial design. Onco Targets Ther. 2016;9:203-10. https://doi.org/10.2147/OTT.S89967. PubMed Central: PMC4708174. PubMed:26793003.

19. Nitulescu GM, Margina D, Juzenas P, Peng Q, Olaru OT, Saloustros E, Fenga C, Spandidos D, Libra M, Tsatsakis AM. Akt inhibitors in cancer treatment: The long journey from drug discovery to clinical use (Review). Int J Oncol. 2016;48(3):869-85. https://doi.org/10.3892/ijo.2015.3306. PubMed Central: PMC4750533. PubMed: 26698230.

20. Boswell-Smith V, Spina D, Page CP. Phosphodiesterase inhibitors. Br J Pharmacol. 2006;147 Suppl 1:252-7. https://doi.org/10.1038/sj.bjp. 0706495. PubMed Central: PMC1760738. PubMed: 16402111.

21. Schmidt DT, Watson N, Dent G, Ruhlmann E, Branscheid D, Magnussen H, Rabe KF. The effect of selective and non-selective phosphodiesterase inhibitors on allergen- and leukotriene C(4)-induced contractions in passively sensitized human airways. Br J Pharmacol. 2000;131(8):1607-18. https://doi.org/10.1038/sj.bjp.0703725. PubMed Central: PMC1572487. PubMed:11139438. 
22. Maurice DH, Ke H, Ahmad F, Wang Y, Chung J, Manganiello VC. Advances in targeting cyclic nucleotide phosphodiesterases. Nat Rev Drug Discov. 2014;13(4):290-314. https://doi.org/10.1038/nrd4228. PubMed Central: PMC4155750. PubMed: 24687066.

23. Yamanaka Y, Mammoto T, Kirita T, Mukai M, Mashimo T, Sugimura M, Kishi Y, Nakamura H. Epinephrine inhibits invasion of oral squamous carcinoma cells by modulating intracellular cAMP. Cancer Lett. 2002;176(2):143-8. PubMed: 11804741.

24. Murata K, Kameyama M, Fukui F, Ohigashi H, Hiratsuka M, Sasaki Y, Kabuto T, Mukai M, Mammoto T, Akedo H, Ishikawa O, Imaoka S. Phosphodiesterase type III inhibitor, cilostazol, inhibits colon cancer cell motility. Clin Exp Metastasis. 1999;17(6):525-30. PubMed: 10763919.

25. McEwan DG, Brunton VG, Baillie GS, Leslie NR, Houslay MD, Frame MC. Chemoresistant KM12C colon cancer cells are addicted to low cyclic AMP levels in a phosphodiesterase 4-regulated compartment via effects on phosphoinositide 3-kinase. Cancer Res. 2007;67(11):5248-57. https://doi. org/10.1158/0008-5472.CAN-07-0097. PubMed: 17545604.

26. Timoshenko AV, Xu G, Chakrabarti S, Lala PK, Chakraborty C. Role of prostaglandin $\mathrm{E} 2$ receptors in migration of murine and human breast cancer cells. Exp Cell Res. 2003;289(2):265-74. PubMed: 14499627.

27. Kelly K, Mejia A, Suhasini AN, Lin AP, Kuhn J, Karnad AB, Weitman S, Aguiar RC. Safety and Pharmacodynamics of the PDE4 Inhibitor Roflumilast in Advanced B-cell Malignancies. Clin. Cancer Res. 2017;23(5): 1186-92. https://doi.org/10.1158/1078-0432.CCR-16-1207. PubMed Central: PMC5316514. PubMed: 27542768.

28. Bar-Shavit R, Maoz M, Kancharla A, Nag JK, Agranovich D, Grisaru-Granovsky S, Uziely B. G Protein-Coupled Receptors in Cancer. Int J Mol Sci. 2016;17(8):. https://doi.org/10.3390/ijms17081320. PubMed Central: PMC5000717. PubMed: 27529230

29. Dorsam RT, Gutkind JS. G-protein-coupled receptors and cancer. Nat Rev Cancer. 2007;7(2):79-94. https://doi.org/10.1038/nrc2069. PubMed: 17251915.

30. Lum L, Beachy PA. The Hedgehog response network: sensors, switches, and routers. Science. 2004;304(5678):1755-9. https://doi.org/10.1126/ science.1098020. PubMed: 15205520.

31. Ruiz i Altaba A, Sanchez P, Dahmane N. Gli and hedgehog in cancer: tumours, embryos and stem cells. Nat Rev Cancer. 2002;2(5):361-72. https://doi.org/10.1038/nrc796. PubMed:12044012.

32. Kasai K, Takahashi M, Osumi N, Sinnarajah S, Takeo T, Ikeda H, Kehrl JH, Itoh $\mathrm{G}$, Arnheiter $\mathrm{H}$. The $\mathrm{G} 12$ family of heterotrimeric $\mathrm{G}$ proteins and Rho GTPase mediate Sonic hedgehog signalling. Genes Cells. 2004;9(1):49-58. PubMed: 14723707.

33. Riobo NA, Saucy B, Dilizio C, Manning DR. Activation of heterotrimeric $G$ proteins by Smoothened. Proc Natl Acad Sci USA. 2006;103(33):12607-12. https://doi.org/10.1073/pnas.0600880103. PubMed Central: PMC1567926. . PubMed: 16885213.

34. Nusse R. Wnt signaling in disease and in development. Cell Res. 2005;15(1): 28-32. https://doi.org/10.1038/sj.cr.7290260. PubMed: 15686623.

35. Moon RT, Kohn AD, De Ferrari GV, Kaykas A. WNT and beta-catenin signalling: diseases and therapies. Nat Rev Genet. 2004;5(9):691-701. https://doi.org/10.1038/nrg1427. PubMed: 15372092.

36. Chen W, Ren XR, Nelson CD, Barak LS, Chen JK, Beachy PA, de Sauvage F, Lefkowitz RJ. Activity-dependent internalization of smoothened mediated by beta-arrestin 2 and GRK2. Science. 2004;306(5705):2257-60. https://doi.org/10.1126/science.1104135. PubMed: 15618519 .

Ready to submit your research? Choose BMC and benefit from:

- fast, convenient online submission

- thorough peer review by experienced researchers in your field

- rapid publication on acceptance

- support for research data, including large and complex data types

- gold Open Access which fosters wider collaboration and increased citations

- maximum visibility for your research: over $100 \mathrm{M}$ website views per year

At $\mathrm{BMC}$, research is always in progress.

Learn more biomedcentral.com/submissions 